\title{
Changes in ice thickness and flow velocity of Yala Glacier, Langtang Himal, Nepal, from 1982 to 2009
}

\author{
Shin SUGIYAMA, ${ }^{1}$ Kotaro FUKUI, ${ }^{2}$ Koji FUJITA, ${ }^{3}$ Kenta TONE, ${ }^{1,4}$ Satoru YAMAGUCHI ${ }^{5}$ \\ ${ }^{1}$ Institute of Low Temperature Science, Hokkaido University, Sapporo, Japan \\ E-mail: sugishin@lowtem.hokudai.ac.jp \\ ${ }^{2}$ Tateyama Caldera Sabo Museum, Tateyama-cho, Toyama, Japan \\ ${ }^{3}$ Graduate School of Environmental Studies, Nagoya University, Nagoya, Japan \\ ${ }^{4}$ Graduate School of Environmental Science, Hokkaido University, Sapporo, Japan \\ ${ }^{5}$ Snow and Ice Research Center, National Research Institute for Earth Science and Disaster Prevention, Nagaoka, Japan
}

\begin{abstract}
To investigate recent glacier changes in the Himalayan region, we carried out GPS and ground-penetrating radar (GPR) measurements at Yala Glacier, a benchmark glacier in Nepal. Glacier surface elevation and ice thickness were surveyed along a $1.5 \mathrm{~km}$ profile from the glacier top to the terminus. Ice flow velocity was measured at five locations by surveying stakes for either 1 year or $\mathbf{4}$ day periods. Obtained surface elevation and ice velocity were compared with those measured in 1982 and 1996. The mean ice thickness along the radar profile was $36 \mathrm{~m}$ in 2009 and the ice has been thinning at rates of $-0.69 \pm 0.25$ and $-0.75 \pm 0.24 \mathrm{ma}^{-1}$ during the periods $1982-96$ and $1996-2009$, respectively. The thinning rate increases down-glacier, reaching a magnitude up to $-1.8 \mathrm{~m} \mathrm{a}^{-1}$ near the terminus from 1996 to 2009. The ice velocity has reduced by $>70 \%$ from 1982 to 2009 in the lower half of the glacier. By assuming a constant driving stress over the glacier, the total ice volume in 2009 was estimated as $0.061 \mathrm{~km}^{3}$. Our results indicate that Yala Glacier has lost $\sim 40 \%$ of its ice volume over the last 27 years and that the rate of the mass loss has accelerated over the last decade.
\end{abstract}

\section{INTRODUCTION}

Lack of information regarding mass change in Himalayan glaciers is one of the main causes of uncertainties in the contribution of mountain glaciers to current and future sealevel rise. Ice mass loss in this region over past decades was estimated by several studies on the basis of satellite and field data with the aid of mass-balance modelling (e.g. Dyurgerov, 2010; Radić and Hock, 2011), as well as satellite gravimetric measurements (Matsuo and Heki, 2010; Jacob and others, 2012). However, these studies yielded significantly different estimates with relatively large uncertainties. The primary reason for the discrepancy and ambiguity is insufficient field data, which hampers the understanding of processes controlling glacier changes in the Himalaya. In situ data are important for this region because of the uniqueness and diversity of geographical conditions (e.g. monsoon climate, summer accumulation, high elevation and debris-covered surface). Nevertheless, field observations of the Himalayan glaciers are sparse in space and time.

The Nepal Himalaya form the central part of the Himalayan mountain system. High mountains with deeply incised terrain accommodate a large number of glaciers, which are frequently covered by debris. The glacier mass balance is dominated by Indian monsoon, and thus summer accumulation regime is a characteristic feature in this region (Ageta and Higuchi, 1984; Fujita, 2008). Glacier changes are of particular importance for Nepal, not merely because glacier runoff is an essential water resource in mountain areas, but also because it influences the discharge in lowland rivers. Studies based on satellite imagery showed that the glaciers have been retreating and losing mass since the 1970s (Bolch and others, 2011; Scherler and others, 2011; Nuimura and others, 2012), but accurate estimation of glacier volume change is still difficult because satellite-derived surface elevation is often insufficiently accurate. Detailed analysis of the mechanisms that control changes in glaciers is also difficult because essential information (e.g. ice velocity, ice thickness and mass balance) is usually unavailable.

In the Nepal Himalaya, reliable long-term ground-based data are available from only a limited number of glaciers. Yala Glacier has been the focus of several studies since the 1980s (e.g. Ageta and others, 1984; Higuchi, 1984) and thus is regarded as a benchmark glacier in the region. Together with data from two other glaciers in Nepal, surface elevation data from Yala Glacier were used to compute mass-balance variations over the three decades since the 1970s (Fujita and Nuimura, 2011). The results showed spatially non-uniform distributions of mass balance over the Nepal Himalaya, and the data from Yala Glacier represented the changes in the glaciers in a relatively humid environment at lower altitudes. The aim of this paper is to report the observational data from the 2009 field campaign on Yala Glacier. We present the results of a ground-penetrating radar (GPR) ice thickness survey performed for the first time on this glacier. The GPR data were used to estimate the total ice volume of the glacier by several methods. We also compared surface elevation and ice velocity with those measured in previous campaigns to discuss their changes since 1982. Surface elevation change over Yala Glacier was presented by Fujita and Nuimura (2011), but we focus the study on our GPR survey route to investigate the details of ice thickness change and its influence on the ice dynamics.

\section{METHOD}

\section{Study site}

Yala Glacier is located in the Langtang valley in northcentral Nepal (Fig. 1). The glacier covers a southwest-facing slope over an area of $1.82 \mathrm{~km}^{2}$ in 2006 and an elevation range of $5000-5600 \mathrm{~m}$ a.s.l. It is one of the most frequently 

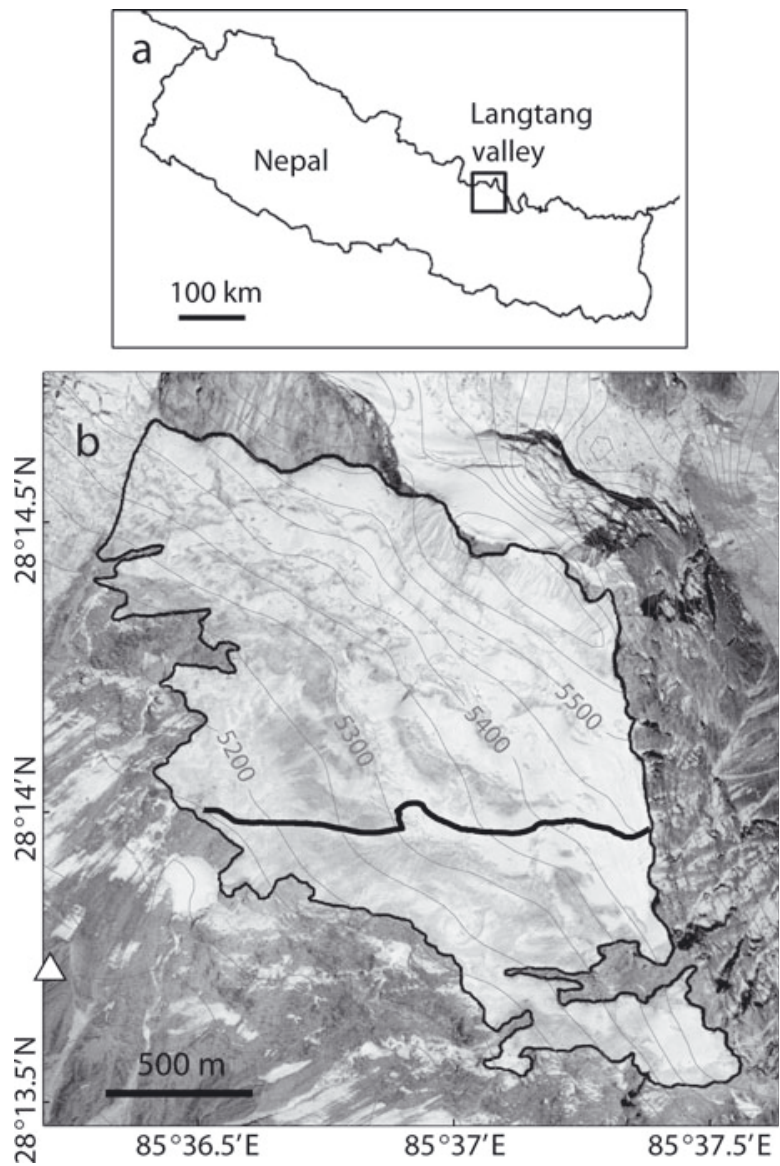

Fig. 1. (a) Map of Nepal showing the location of the study site. (b) A satellite image of Yala Glacier taken on 3 January 2006 (data source: Google Earth). The bold curve on the glacier indicates the GPR and GPS survey route, and the triangle shows the location of the GPS reference station. Contours show surface elevation with intervals of $50 \mathrm{~m}$.

studied glaciers in the Himalaya. The research conducted here includes an ice-core drilling project undertaken in 1981 and 1982 (Watanabe and others, 1984) and massbalance, ice flow and climatic observations in the 1980s and 1990s (Steinegger and others, 1993; Nakawo and others, 1997; Fujita and others, 1998). The ice thickness is known to be 30 and $60 \mathrm{~m}$ at two ice-core drilling sites (Fig. 2a) (Watanabe and others, 1984), but ice radar measurements have never been carried out. Borehole observations showed that ice was temperate at the upper drilling site and slightly cold $\left(\sim-1{ }^{\circ} \mathrm{C}\right)$ at the lower site (Watanabe and others, 1984; Ozawa, 1991). The glacier has been thinning since the 1980s, and the rate of thinning has been increasing (Fujita and others, 1998; Fujita and Nuimura, 2011).

\section{Ice thickness}

We employed GPR (Geophysical Survey Systems Inc., SIR3000) with a centre frequency of $270 \mathrm{MHz}$ to measure ice thickness. The field measurement was carried out on 1 November 2009. The instrument was mounted on a sledge, which was towed along a survey route from the top of the glacier to the terminus (Figs 1 and 2). The route was diverted to the north at an elevation between 5300 and $5350 \mathrm{~m}$ because of crevasses. Antennas enclosed in a box were aligned perpendicular to the survey route. Radar echo signals were recorded with a scanning frequency of $24 \mathrm{~Hz}$ (2048 samples per scan) and processed using Radan 7

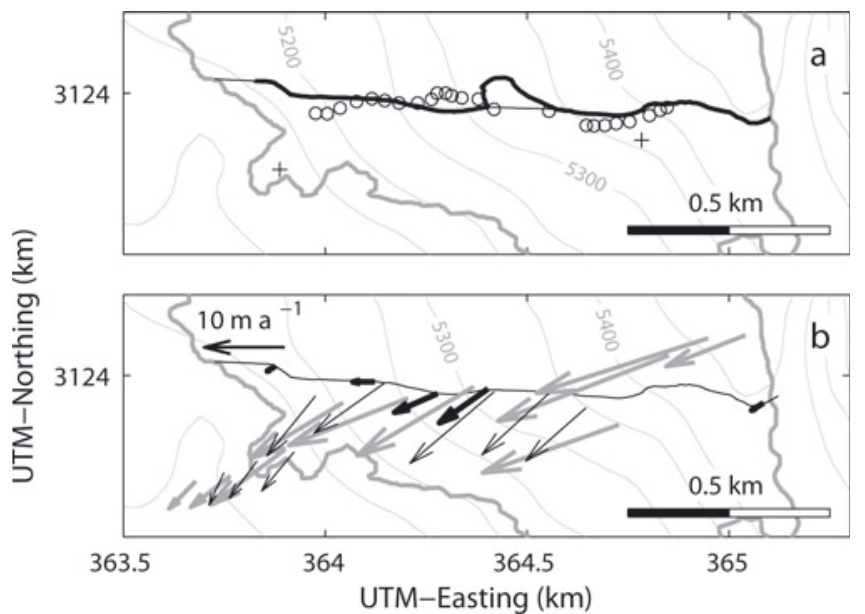

Fig. 2. Maps showing the GPR and GPS survey route in 2009 (bold black curve): (a) surface elevation survey sites in 1996 (open circles) and 1981 and 1982 borehole sites (crosses); (b) ice flow vectors in 2009 (bold black arrows), 1996 (thin black arrows) and 1982 (bold grey arrows). Ice surface elevation and thickness were interpolated along the thin black curve to present the data in Figures 4 and 5 . Contours show surface elevation at intervals of $50 \mathrm{~m}$. The velocities in (b) were measured at the origins of the vectors. The coordinates are in Universal Transverse Mercator (UTM) zone $45 \mathrm{~N}$

software for Windows (Geophysical Survey Systems Inc.). We determined the two-way travel time of return waves from the bed by carefully inspecting a radargram. Ice thickness was computed from the travel time by assuming a wave velocity in a glacier as $170 \mathrm{~m} \mathrm{\mu s}^{-1}$. An ice thickness profile along the route was obtained using the GPS survey data described in the following subsection. An error due to uncertainty in the reflection peaks in the radargram was evaluated as $\pm 0.9 \mathrm{~m}$ from repeated identification of the peak locations. We also expect errors due to ambiguity in the wave velocity, GPS positioning errors and vertical resolution limited by the wavelength. As a sum of these, the maximum error in the ice thickness measurement was estimated as $1.5 \mathrm{~m}$ plus $2 \%$ of ice thickness.

\section{Surface elevation}

Glacier surface elevation was measured along the GPR survey route using paired GPS equipment. A GPS antenna and receiver (Magellan, ProMark3) were mounted on a backpack carried by a surveyor, and the continuously recorded GPS satellite signals were post-processed with those from a reference GPS station (GNSS Solutions, GEM-1) installed southwest of the glacier (Fig. 1b). The positioning error in the vertical direction, including uncertainty in the height of the antenna carried by a surveyor, was estimated as $0.3 \mathrm{~m}$ (Fujita and Nuimura, 2011). Errors in the horizontal direction were smaller than this value and negligible for our analyses described below. The surface elevation was compared with that measured in 1982 and 1996 to compute ice thickness changes over the periods. The surface elevation in 1982 was surveyed by ground photogrammetry (Yokoya$\mathrm{ma}, 1984)$ and later digitized into a $10 \mathrm{~m}$ resolution digital elevation model (DEM) (Fujita and Nuimura, 2011). The accuracy of this DEM was reported as $\sim 10 \mathrm{~m}$ (Fujita and Nuimura, 2011). The 1982 DEM was interpolated to the 2009 GPR survey route to compute the elevation change from 1982 to 2009. Because the 1996 survey sites are not exactly on our survey route (Fig. 2a) (Fujita and others, 


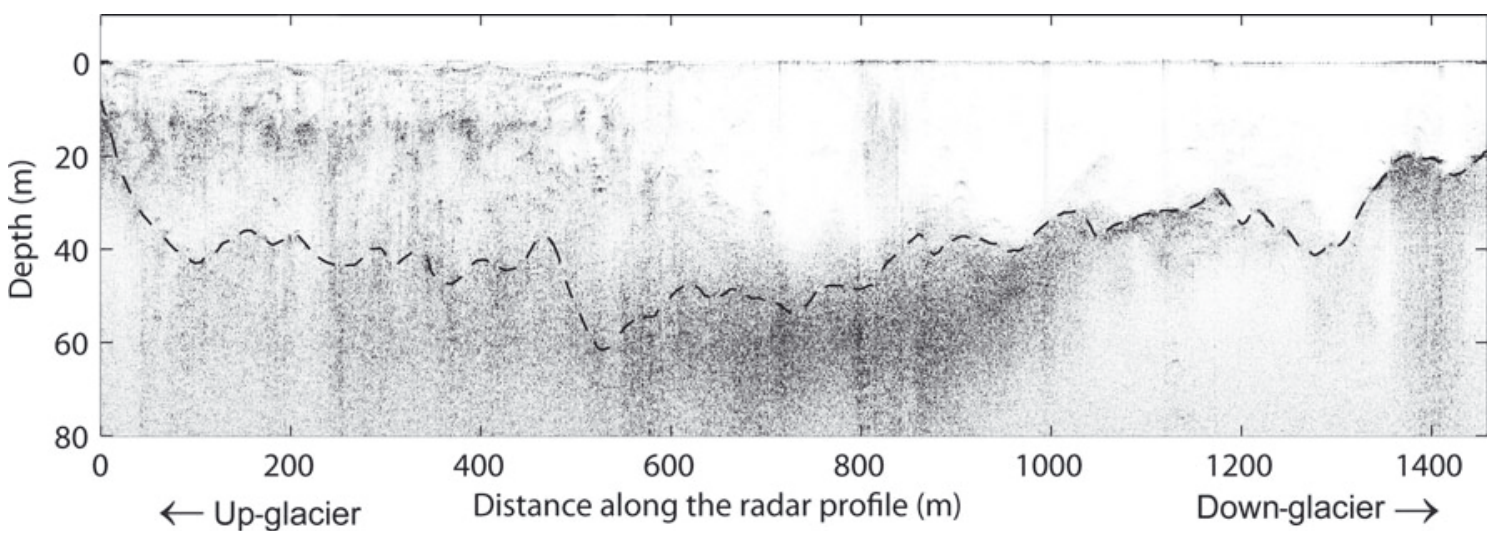

Fig. 3. A GPR radargram along the survey route. The intensity of the reflection power is represented by an arbitrary greyscale.

1998), we compared the 1996 and 2009 data at the same surface elevation according to an Advanced Spaceborne Thermal Emission and Reflection Radiometer (ASTER) DEM in 2003 (i.e. 1996 and 2009 survey sites that were compared were at the same elevation in the 2003 DEM). This procedure assumes an equal ice thickness change at the same surface level. The ASTER DEM was generated by stereographic analysis of ASTER images and distributed by the Earth Remote Sensing Data Analysis Center in Japan. The root-mean-square error of the DEM is typically in the range 10-20 m (Fujita and others, 2008). The GPS data in 2009 were also used to locate the GPR data.

\section{Ice flow velocity}

Ice flow velocity was measured by surveying stakes installed at five locations on the glacier (Fig. 2b). The upper three stakes were installed on 26 September 2008 and resurveyed on 31 October 2009, with kinematic GPS measurements (Magellan, ProMark3). The lower two stakes were surveyed for 4 days from 31 October to 4 November 2009, with dualfrequency static GPS measurements (Leica, System 1200). The GPS measurements were performed using reference GPS receivers located at $\sim 500 \mathrm{~m}$ from the glacier margin (Fig. 1b), and the baseline length of the relative positioning was within $2 \mathrm{~km}$. Positioning errors in the kinematic and static GPS measurements were $0.3 \mathrm{~m}$ and $2 \mathrm{~mm}$ in the horizontal plane. Accordingly, errors in the computed velocity were within $3 \%$ and $16 \%$ for the upper three and lower two measurement sites, respectively.

\section{RESULTS}

\section{Ice thickness}

Figure 3 shows the intensity of GPR return signals along the survey route. The glacier bed was clearly identified by a transition from low to high return power at a certain depth in the lower half of the glacier. In contrast, the reflection from the bed was less clear and obscured by englacial return signals in the upper portion. We identified the bed reflection as much as possible in these regions by taking return power maxima, which were observed continuously up- and downglacier. The GPR survey route followed a detour in the middle of the glacier to bypass crevasses. Hereafter, the detour was eliminated and the data blank near the terminus was interpolated, i.e. the bed and surface profiles are analyzed and depicted along the thin line in Figure 2. The mean ice thickness along the corrected route was $36 \mathrm{~m}$ and the maximum ice thickness was $61 \pm 3 \mathrm{~m}$ at $530 \mathrm{~m}$ from the top of the glacier. Bed elevation was obtained as shown in Figure $4 \mathrm{a}$ by subtracting the thickness from the surface
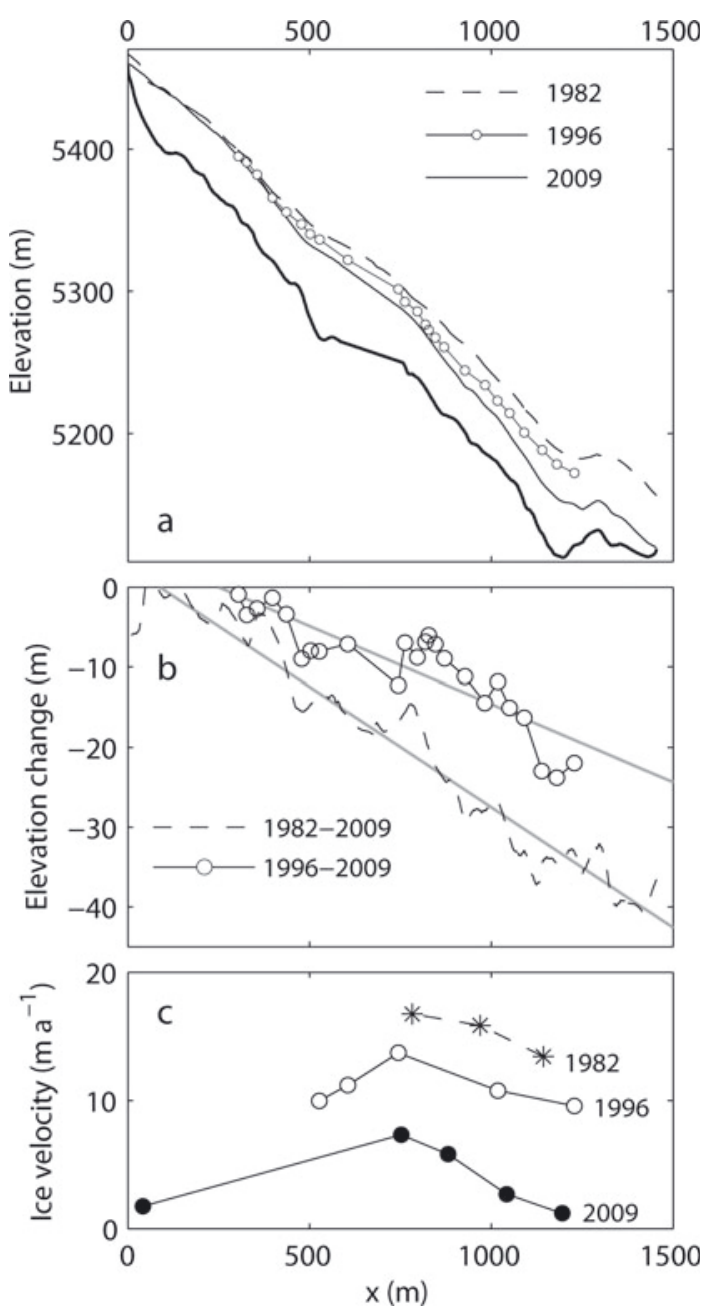

Fig. 4. (a) Surface elevation measured in 1982 (dashed curve), 1996 (solid curve with open circles) and 2009 (solid curve). The bold curve indicates the bed elevation. (b) Change in surface elevation from 1982 to 1996 (open circles) and from 1982 to 2009 (dashed curve). The grey lines are linear regressions of the data. (c) The horizontal component of ice flow velocity in 2009 (solid circles), 1996 (open circles) and 1982 (asterisks). The 1982 and 1996 velocities are only those measured within $50 \mathrm{~m}$ from the 2009 survey route. 


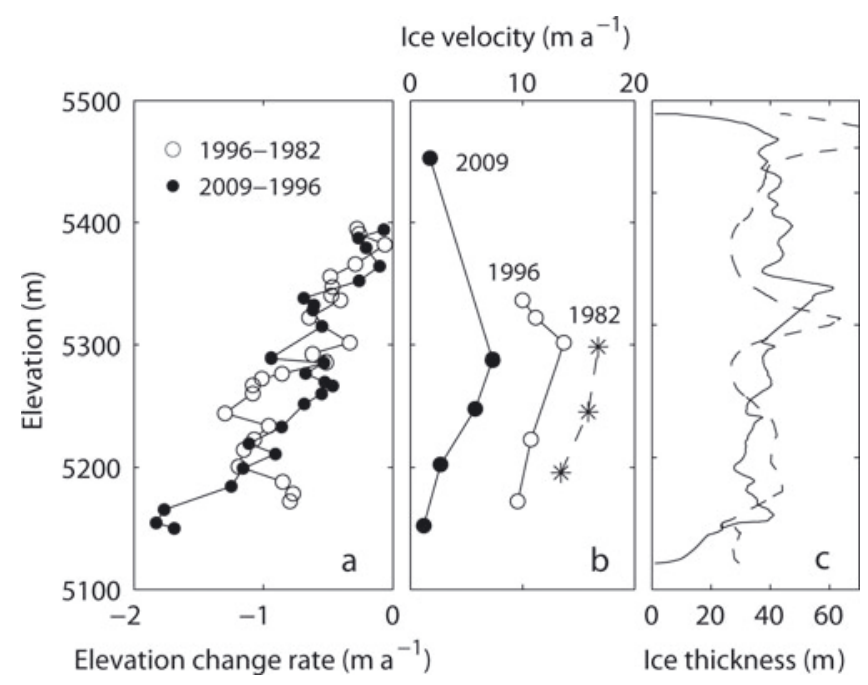

Fig. 5. (a) Change in surface elevation from 1982 to 1996 (open circles) and from 1996 to 2009 (solid circles); (b) the horizontal component of ice flow velocity in 2009 (solid circles), 1996 (open circles) and 1982 (asterisks); and (c) ice thickness along the survey route measured with GPR (solid curve) and computed with a constant driving-stress assumption (dashed curve). Surface elevation coordinates are in the years of the second measurements for (a) and (b) and in 2009 for (c).

elevation measured by GPS. Owing to a bed depression at $500-600 \mathrm{~m}$ from the top of the glacier, relatively thick ice is present in this region. The bed slopes upwards (to the direction of ice flow) near the terminus at 1200-1300 m, which accompanies a depression in the surface.

\section{Surface elevation}

Glacier surface elevation obtained in this study was compared with the values measured in 1982 and 1996 (Fig. 4a). The results show that the surface has been continuously lowering since 1982 and that the magnitude of the change was greater down-glacier. The greatest change is found near the terminus, which is $\sim-40 \mathrm{~m}$ over the 27 years from 1982 to 2009 (Fig. 4b). The magnitude decreases up-glacier, approaching zero near the top of the survey route. The magnitude of elevation change within the upper $400 \mathrm{~m}$ of the glacier is less than $-3.5 \mathrm{~m}$ for 1996-2009 and $-7.5 \mathrm{~m}$ for $1982-2009$. Mean rates of elevation change over the survey route were computed by assuming a linear relationship between the surface elevation change $\Delta z$ and the distance from the top $x$ (Fig. 4b). Obtained relationships are $\Delta z=-0.0195 x+4.87 \mathrm{~m}$ for 1996-2009 and $\Delta z=$ $0.0302 x+2.66 \mathrm{~m}$ for $1982-2009$. Assuming $\Delta z=0$ in the upper reaches, where the linear functions give positive values, the mean rates along the survey route were $-0.75 \pm 0.24 \mathrm{ma}^{-1}$ for 1996-2009 and $-0.72 \pm 0.09 \mathrm{~m} \mathrm{a}^{-1}$ for $1982-2009\left(-0.69 \pm 0.25 \mathrm{~m} \mathrm{a}^{-1}\right.$ for $1982-96$ as a residual). The uncertainties were estimated from the standard deviation of the data from the linear regression in Figure $4 \mathrm{~b}$.

\section{Ice flow velocity}

Measured flow velocities are shown in Figures $2 \mathrm{~b}$ and $4 \mathrm{c}$, together with those from 1982 and 1996 (Ageta and others, 1984; Fujita and others, 1998). The 1982 and 1996 data in Figure 4c are only those measured within $50 \mathrm{~m}$ of the 2009 survey route. The glacier has slowed down significantly since the previous measurements. The change in velocity from 1982 to 2009 ranged from -10 to $-12 \mathrm{ma}^{-1}$ in the lower half of the glacier $(x>700 \mathrm{~m})$. This is equivalent to a $60-90 \%$ velocity reduction. Most of the velocities were not measured for an annual interval (October-November at the lower two stakes in 2009, May-October in 1996 and September-October in 1982), which leaves the possibility that the velocities were influenced by seasonal variations. Nevertheless, the influence of the short measurement period on the velocity is probably insignificant since the bed is frozen in the ablation area according to the drilling in the 1980s (Watanabe and others, 1984). Moreover, the observed velocity changes are much greater than those explained by possible seasonal variations.

\section{DISCUSSION}

Our results showed that Yala Glacier has been losing ice mass since 1982 and that the rate of mass loss is not uniform over the glacier. The ice thinning rate is clearly dependent on the glacier surface elevation (Fig. 5a). The relationships between the thinning rate and elevation in 1982-96 and 1996-2009 are similar in the elevation range from 5200 to $5400 \mathrm{~m}$. However, the magnitude of the thinning rate in 1996-2009 is greater than that in 1982-96 near the terminus in the region below 5200 ma.s.I. Such variations in the elevation change, i.e. gradual increase from high to low elevations and greater increase near the terminus, are commonly observed on other debris-free Himalayan glaciers (Fujita and Nuimura, 2011). Considering that the ice was relatively thin and slow-moving at $\sim 5200$ ma.s.l. in 2009 (Fig. 5b and c), only a little ice mass was advected into the lower elevation range. Thus, the reduction in down-glacier ice flux might have caused a decrease in vertical strain rate and a significant increase in thinning rate near the terminus, as has been reported in a valley glacier in the European Alps (Berthier and Vincent, 2012).

The mean ice velocity at 5120-5300 ma.s.l. reduced by $29 \%$ and $62 \%$ from 1982 to 1996 and from 1996 to 2009, respectively (Fig. 5b). Presumably, the most important driver of this deceleration is glacier thinning. The mean ice thickness in this elevation range was $60 \mathrm{~m}$ in 1982, which decreased to $45 \mathrm{~m}$ in 1996 and $31 \mathrm{~m}$ in 2009. If we assume ice flow was entirely due to viscous deformation and proportional to the fourth power of ice thickness (Cuffey and Paterson, 2010), the velocity reduction expected from the ice thinning is 68\% for 1982-96 and 93\% for 1996-2009. Apparently, the observed velocity change is smaller than this estimation, probably because the ice surface has been steepening because of greater elevation change in the lower reaches of the glacier. The surface slope is another important factor in the ice deformation rate, and thus surface steepening partly compensated the deceleration due to ice thinning. In addition to the geometrical conditions, changes in ice thermal structure since the 1980s have to be taken into account. The borehole temperature measurements in 1981 and 1982 showed that ice was temperate in the accumulation zone while it was cold in the ablation zone (Watanabe and others, 1984; Ozawa, 1991). Such polythermal structure is expected to be influenced by ice thinning as well as warming climate conditions. For example, ice temperature might have decreased after the glacier thinning, which has potentially reduced the ice velocity. On the other hand, meltwater increase due to warming might have enhanced basal sliding over a temperate bed. 
GPR bed reflection was not clearly observed in the upper half of the glacier. Presumably, wave transmission and scattering within the ice were influenced by the thermal structure of the glacier. The drilling in 1982 confirmed that ice was temperate in the upper reach at 5405 ma.s.l. (Fig. 2a) (Watanabe and others, 1984). Thus, we can expect more significant attenuation and scattering by temperate ice as well as snow meltwater percolated into firn and ice. In the lower reaches, cold ice was observed by the drilling in 1981 near the current terminus at $5180 \mathrm{~m}$ a.s.l. (Fig. 2a). This is consistent with our GPR data, i.e. clear reflection from the bed and less scattering within the ice. Our data suggest that Yala Glacier is a polythermal glacier with temperate and cold ice in the upper and lower portions, which agrees with the structure proposed in previous studies (Watanabe and others, 1984; Ozawa, 1991).

The ice thickness measured along the GPR survey route (Fig. 5c) provides a clue to estimate the ice volume of Yala Glacier. If we simply multiply the mean ice thickness $(\bar{h}=36 \mathrm{~m})$ along the route to the surface area obtained from the satellite image in $2006\left(A=1.82 \mathrm{~km}^{2}\right)$, the ice volume is $V=0.066 \mathrm{~km}^{3}$. This value can be regarded as the upper bound because the survey route was taken in the central part of the glacier, where ice is relatively thick. Next, we assume the driving stress $\left(\tau_{\mathrm{d}}=\rho g h \sin \alpha\right.$, where $\rho=910 \mathrm{~kg} \mathrm{~m}^{-3}$ is ice density, $g=9.8 \mathrm{~m} \mathrm{~s}^{-2}$ is the gravitational acceleration, $h$ is ice thickness and $\alpha$ is surface slope) is constant over the glacier and $\tau_{\mathrm{d}}$ is represented by the mean value along the survey route. By using surface slope from the ASTER DEM in 2003 , the mean driving stress along the route was $\overline{\tau_{\mathrm{d}}}=$ $98 \mathrm{kPa}$ and the total ice volume was computed as $A \times \bar{h}=A \times \overline{\tau_{\mathrm{d}}} / \rho g \sin \alpha=0.061 \mathrm{~km}^{3}$. This method overestimates actual values over a flat terrain and near glacier margins. Nevertheless, thickness measured along the survey route is reasonably well reproduced by the computation (Fig. 5c). The computed thickness distribution shows relatively thick ice in the lower middle part of the glacier (Fig. 6). A very similar total ice volume $0.062 \mathrm{~km}^{3}$ was obtained from an equation of area-volume scaling analysis $\left(V=C A^{\gamma}\right)$ by using one of the proposed parameter sets $(c=0.191, \gamma=1.36)$ (Bahr and others, 1997; Radić and Hock, 2010). This choice of parameter values gives a relatively smaller volume estimate by this method among the parameters proposed for mountain glaciers. Another parameter set proposed by Chen and Ohmura (1990) $(c=0.2055, \gamma=1.375)$ gives a volume of $0.083 \mathrm{~km}^{3}$, which is greater than that obtained above from the mean thickness along the survey route. A likely reason why the area-volume scaling analysis tends to overestimate the volume of Yala Glacier is the relatively steep slopes of this glacier. According to these analyses, we propose $0.061 \mathrm{~km}^{3}$ as a likely value and $0.066 \mathrm{~km}^{3}$ as the upper bound for the total ice volume in 2009.

In addition to the elevation data along the GPR survey route presented in this study, Fujita and Nuimura (2011) measured surface elevation extensively in the lowermost region of the glacier to compute the mean thinning rate of Yala Glacier from 1982 to 2009. The area-averaged ice thinning rates were shown as $-0.746 \pm 0.202$ and $-0.879 \pm 0.088 \mathrm{~m} \mathrm{a}^{-1}$ for the periods $1982-96$ and 1996 2009, respectively. If we assume these rates and the ice volume estimated in this study $\left(0.061 \mathrm{~km}^{3}\right.$ in 2009$)$, the total volume loss from 1982 to 2009 corresponds to $43 \pm 5 \%$ of the 1982 volume.

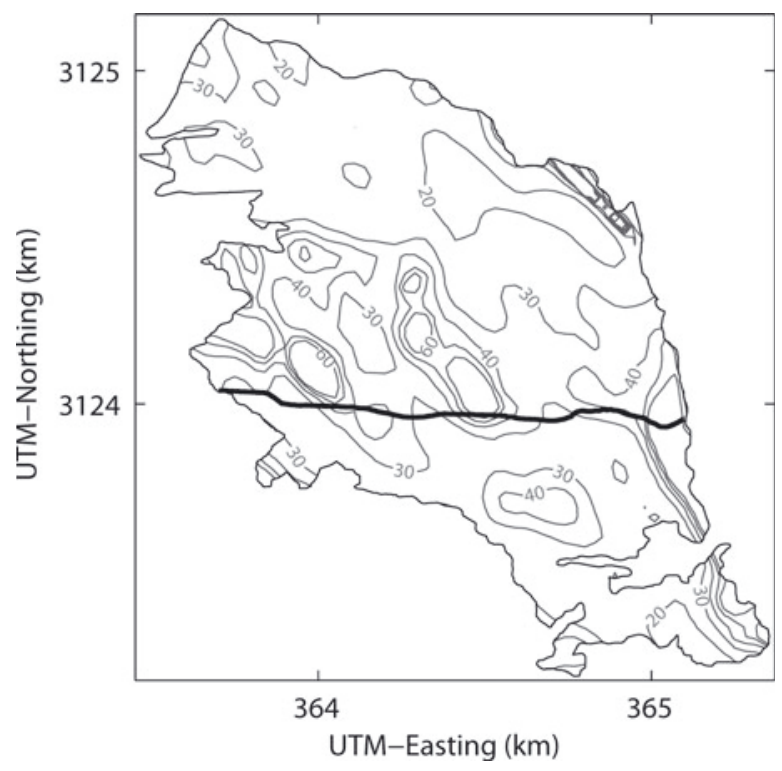

Fig. 6. Ice thickness computed by assuming a constant driving stress. The intervals of the contours are $10 \mathrm{~m}$, and the coordinates are in UTM zone $45 \mathrm{~N}$. The bold curve on the glacier indicates the GPR and GPS survey route.

\section{CONCLUSION}

To contribute to the accurate understanding of recent glacier changes in the Himalaya, surface elevation and ice velocity of Yala Glacier were resurveyed in 2009. The results were compared with those measured in 1982 and 1996. The glacier has been thinning since 1982 at an increasing rate: $-0.69 \pm 0.25 \mathrm{~m} \mathrm{a}^{-1}$ from 1982 to 1996 and $-0.75 \pm 0.24 \mathrm{ma}^{-1}$ from 1996 to 2009 . The magnitude of the thinning rate increased from the top to the lower reaches of the glacier, for example from $-0.3 \mathrm{~m} \mathrm{a}^{-1}$ in the upper $400 \mathrm{~m}$ to $-1.8 \mathrm{~m} \mathrm{a}^{-1}$ near the terminus in 1996-2009. Ice velocity has reduced by $60-90 \%$ from 1982 to 2009 in the lower half of the glacier. The lower reaches of the glacier became steeper as a result of the greater thinning rate down-glacier, suggesting that deceleration due to ice thinning was partly compensated by the steepening surface slope. We also measured ice thickness using GPR along a survey route from the top to the terminus. Mean thickness along the route was $36 \mathrm{~m}$ and the thickest ice $(61 \pm 3 \mathrm{~m})$ was found on a bedrock depression at $530 \mathrm{~m}$ from the top. Assuming a constant driving stress over the glacier, the total ice thickness of the glacier was estimated as $0.061 \mathrm{~km}^{3}$. By assuming this value and the area-averaged thinning rates reported by a previous study (Fujita and Nuimura, 2011), Yala Glacier has lost $\sim 40 \%$ of ice volume from 1982 to 2009.

\section{ACKNOWLEDGEMENTS}

We thank members of the 2009 field campaign for their help in the measurements on Yala Glacier. T. Fukuda helped in satellite data analysis. The manuscript was handled by the scientific editor, A. Booth, and was improved by constructive comments from two anonymous reviewers. This research was funded by the Japanese Ministry of Education, Science, Sports and Culture, Grant-in-Aid for Scientific Research A, 19253001, 2007-10. 


\section{REFERENCES}

Ageta Y and Higuchi K (1984) Estimation of mass balance components of a summer-accumulation type glacier in the Nepal Himalaya. Geogr. Ann. A, 66(3), 249-255

Ageta Y, lida H and Watanabe O (1984) Glaciological studies on Yala Glacier in Langtang Himal. Bull. Glacier Res., 2, 41-47

Bahr DB, Meier MF and Peckham SD (1997) The physical basis of glacier volume-area scaling. J. Geophys. Res., 102(B9), 20355-20362 (doi: 10.1029/97JB01696)

Berthier E and Vincent C (2012) Relative contribution of surface mass-balance and ice-flux changes to the accelerated thinning of the Mer de Glace, French Alps, over 1979-2008. J. Glaciol., 58(209), 501-512 (doi: 10.3189/2012JoG11J083)

Bolch T, Pieczonka T and Benn DI (2011) Multi-decadal mass loss of glaciers in the Everest area (Nepal Himalaya) derived from stereo imagery. Cryosphere, 5(2), 349-358 (doi: 10.5194/tc-5349-2011)

Chen J and Ohmura A (1990) Estimation of Alpine glacier water resources and their change since the 1870s. IAHS Publ. 193 (Symposium at Lausanne 1990 - Hydrology in Mountainous Regions), 127-135

Cuffey KM and Paterson WSB (2010) The physics of glaciers, 4th edn. Butterworth-Heinemann, Oxford

Dyurgerov MB (2010) Reanalysis of glacier changes: from the IGY to the IPY, 1960-2008. Mater. Glyatsiol. Issled./Data Glaciol. Stud. 108, 1-116

Fujita K (2008) Effect of precipitation seasonality on climatic sensitivity of glacier mass balance. Earth Planet. Sci. Lett., 276(1-2), 14-19 (doi: 10.1016/j.epsl.2008.08.028)

Fujita K and Nuimura T (2011) Spatially heterogeneous wastage of Himalayan glaciers. Proc. Natl Acad. Sci. USA (PNAS), 108(34), 14 011-14 014 (doi: 10.1073/pnas.1106242108)

Fujita K, Takeuchi N and Seko K (1998) Glaciological observations of Yala Glacier in Langtang Valley, Nepal Himalayas, 1994 and 1996. Bull. Glacier Res., 16, 75-81

Fujita K, Suzuki R, Nuimura T and Sakai A (2008) Performance of ASTER and SRTM DEMs, and their potential for assessing glacial lakes in the Lunana region, Bhutan Himalaya. J. Glaciol., 54(185), 220-228 (doi: 10.3189/002214308784886162)

Higuchi K (1984) Outline of the glaciological expedition of Nepal: boring project 1981 and 1982. Bull. Glacier Res., 2, 1-5
Jacob T, Wahr J, Pfeffer WT and Swenson S (2012) Recent contributions of glaciers and ice caps to sea level rise. Nature, 482(7386), 514-518 (doi: 10.1038/nature10847)

Matsuo K and Heki K (2010) Time-variable ice loss in Asian high mountains from satellite gravimetry. Earth Planet. Sci. Lett., 290(1-2), 30-36 (doi: 10.1016/j.epsl.2009.11.053)

Nakawo M, Fujita K, Ageta Y, Shankar K, Pokhrel AP and Yao T (1997) Basic studies for assessing the impacts of the global warming on the Himalayan cryosphere, 1994-1996. Bull. Glacier Res., 15, 53-58

Nuimura T, Fujita K, Yamaguchi S and Sharma RR (2012) Elevation changes of glaciers revealed by multitemporal digital elevation models calibrated by GPS survey in the Khumbu region, Nepal Himalaya, 1992-2008. J. Glaciol., 58(210), 648-656 (doi: 10.3189/2012JoG11J061)

Ozawa H (1991) Thermal regime of a glacier in relation to glacier ice formation. (PhD thesis, Hokkaido University)

Radić V and Hock R (2010) Regional and global volumes of glaciers derived from statistical upscaling of glacier inventory data. J. Geophys. Res., 115(F1), F01010 (doi: 10.1029/ 2009JF001373)

Radić V and Hock R (2011) Regionally differentiated contribution of mountain glaciers and ice caps to future sea-level rise. Nature Geosci., 4(2), 91-94 (doi: 10.1038/ngeo1052)

Scherler D, Bookhagen B and Strecker MR (2011) Spatially variable response of Himalayan glaciers to climate change affected by debris cover. Nature Geosci., 4(3), 156-159 (doi: 10.1038/ ngeo1068)

Steinegger U, Braun LN, Kappenberger G and Tartari G (1993) Assessment of annual snow accumulation over the past 10 years at high elevations in the Langtang region. IAHS Publ. 218 (Symposium at Kathmandu 1992 - Snow and Glacier Hydrology), 155-165

Watanabe O, Takenaka S, lida H, Kamiyama K, Thapa KB and Mulmi DD (1984) First results from Himalayan glacier boring project in 1981-1982. Part I. Stratigraphic analyses of full-depth cores from Yala Glacier, Langtang Himal, Nepal. Bull. Glacier Res., 2, 7-23

Yokoyama K (1984) Ground photogrammetry of Yala glacier, Langtang Himal, Nepal Himalaya. Bull. Glacier Res., 2, 99-105 